\title{
Secretory Function of the Vestibular Nerve Calyx Suggested by Presence of Vesicles, Synapsin I, and Synaptophysin
}

\author{
E. Scarfone, ${ }^{1}$ D. Demêmes, ${ }^{1}$ R. Jahn, ${ }^{2}$ P. De Camilli, ${ }^{3}$ and A. Sans ${ }^{1}$ \\ ${ }^{1}$ INSERM, U 254, Laboratoire de Neurophysiologie Sensorielle, U.S.T.L., 34060 Montpellier, France, ${ }^{2}$ Max-Planck-Institut für \\ Psychiatrie, Abteilung Neurochemie, 8033 Martinsried bei München, Federal Republic of Germany, and ${ }^{3}$ Department of \\ Medical Pharmacology, CNR Center of Cytopharmacology, University of Milan, 20129 Milan, Italy
}

\begin{abstract}
Type I sensory hair cells of the vestibular epithelium are nearly completely ensheathed by an afferent nerve ending, the vestibular nerve calyx. We have recently reported that the nerve calyx and, in particular, its apical portions surrounding the neck of the hair cell, are immunoreactive for synapsin I (Favre et al., 1986), a major membrane component of small synaptic vesicles of axonal endings. We have now found, by electron microscopy, that the same region of the calyx is densely populated by microvesicles morphologically similar to typical presynaptic small synaptic vesicles. Furthermore, we have established by light microscopy immunocytochemistry that this region of the calyx also contains a high concentration of synaptophysin, another well-characterized major component of small synaptic vesicle membranes. These results suggest that the upper portion of the calyx is equipped with the machinery that in presynaptic terminals is involved in the release of neurotransmitters and raise the possibility that the calyx, via secretion of neurotransmitterlike substances, might modulate the function of type I hair cells.
\end{abstract}

The vestibular sensory hair cells are mechanoelectrical transducers responsible for the perception of linear and angular accelerations. Avian and mammalian amphore-shaped type I sensory hair cells are nearly completely ensheathed by a calyx-shaped nerve ending formed by the peripheral extension of Scarpa ganglion primary afferent neuron (Wersäll and BaggerSjöbäck, 1974). The functional significance of the unique morphology of the nerve calyx is still unknown. A junctional specialization between the basal portion of the hair cell and the basal part of the nerve calyx involving a parallel apposition of the 2 membranes with intervening dense material has been described (Hamilton, 1968; Favre and Sans, 1979). This membrane specialization stops at approximately two-thirds of the cell height, but the upper part of the nerve calyx continues to enclose the neck portion of type I hair cell tightly up to its subapical region (see Fig. 1a). Signal transmission from the type I hair cell to the nerve calyx is thought to occur at the basal part

\footnotetext{
Received Jan. 19, 1988; revised Apr. 13, 1988; accepted Apr. 15, 1988.

We wish to thank D. Favre and D. Bagger-Sjöbäck for useful comments on this work, P. Atger for technical assistance in electron microscopy, and $\mathbf{J}$. Boyer for secretarial assistance. This study was supported in part by grants from the Italian Research Council and from MDA to P.DeC.

Correspondence should be addressed to Eric Scarfone, INSERM, U 254, Laboratoire de Neurophysiologie Sensorielle, U.S.T.L., Place Eugène Bataillon, F-34060 Montpellier Cedex, France.
}

Copyright (C) 1988 Society for Neuroscience $0270-6474 / 88 / 124640-06 \$ 02.00 / 0$ of the cell (Hamilton, 1968), where the junctional specialization is localized. So far the function of the apical part of the calyx remains obscure.

In a previous study (Favre et al., 1986), we used light microscopy immunocytochemistry to investigate the distribution of synapsin $I$ in vestibular sensory epithelia. Synapsin $I$ is a neuron-specific phosphoprotein peripherally associated with the cytoplasmic surface of small synaptic vesicles (De Camilli et al., 1983a, b; Huttner et al., 1983; Navone et al., 1984). We found that synapsin I was present not only in efferent endings that establish synaptic contacts with the cell bodies of type II hair cells and with afferent fibers, but also in the nerve calyces themselves, particularly in their most apical region. The latter result was intriguing in view of the postsynaptic nature of the calyx and prompted us to investigate whether presence of synapsin I in the nerve calyx was also related to presence of synaptic vesicles. To address this question, we first performed an electron microscopic analysis of vestibular epithelia of adult mice and cats in order to determine if synaptic vesiclelike organelles were present in the calycess. Second, we investigated by light microscopy immunocytochemistry whether a well-characterized, major intrinsic transmembrane protein of small synaptic vesicles, synaptophysin (protein p38) (Jahn et al., 1985; Wiedenmann and Franke, 1985; Navone et al., 1986; Leube et al., 1987; Südhof et al., 1987), was also present in nerve calyces.

\section{Materials and Methods}

Electron microscopy. Adult feline vestibular epithelia were fixed by the double-fixation procedure described by Favre and Sans (1983). Briefly, 6-month-old cats were operated on under deep pentobarbital anesthesia, and the lateral semicircular canal was opened. A mixture of fixative solution consisting of $2 \%$ formaldehyde (freshly prepared from paraformaldehyde), $1 \%$ glutaraldehyde, and $1 \%$ dimethylsulfoxide in $0.1 \mathrm{M}$ phosphate buffer ( $\mathrm{pH} \mathrm{7.4;} \mathrm{room} \mathrm{temperature)} \mathrm{was} \mathrm{slowly} \mathrm{injected} \mathrm{into}$ the membraneous labyrinth while at the same time the same mixture of solution was perfused through the ascending aorta. The vestibular receptors were dissected out, immersed for $1 \mathrm{hr}$ in the same mixture of fixative solution, and postfixcd for $2 \mathrm{hr}$ in $1.0 \%$ osmium tetroxide. The specimens were subsequently dehydrated in graded alcohol and embedded in Epon. Ultrathin $(60 \mathrm{~nm})$ and thin $(150 \mathrm{~nm})$ sections were made on an LKB 2088 Ultratome and processed for electron microscopy. Adul mice vestibular sensory epithelia were fixed by immersion for $3 \mathrm{hr}$ in the same mixture of fixative solution used for cat epithelia and similarly processed for electron microscopy.

Light microscopic immunocytochemistry. One- to six-month-old mice and rats and 3- to 8-month-old cats were transcardially perfused under deep pentobarbital anesthesia with a solution of $4 \%$ formaldehyde (freshly prepared from paraformaldehyde), $1 \%$ dimethylsulfoxide in $0.1 \mathrm{M}$ phosphate buffer ( $\mathrm{pH} 7.4$; room temperature). The vestibular epithelia were rapidly dissected out and subsequently postfixed for $2 \mathrm{hr}$ in the same solution. Frozen $(10-\mu \mathrm{m}$-thick) and plastic $(1-\mu \mathrm{m}$-thick) sections were 
prepared, and both kinds of sections were processed for immunorhodamine and for immunoperoxidase as described (De Camilli et al., $1983 a, 1984)$. Affinity-purified antibodies directed against synaptophysin (John et al., 1985) and against synapsin I (De Camilli et al., 1983a) were used at the final concentration of $0.1 \mathrm{mg} / \mathrm{ml}$ for immunorhodaminc and $0.05 \mathrm{mg} / \mathrm{ml}$ for immunoperoxidase. Identical concentrations of nonimmune rabbit IgGs were used as controls.

\section{Results}

\section{Electron microscopy}

Electron microscopic observation of mouse and cat vestibular epithelia revealed that in both species pleiomorphic vesicular organelles were present in the calyces. The upper portion of the calyces in particular (Fig. 1, $a, b$ ) contained a large, homogeneous population of spherical vesicles with an average diameter of 40$60 \mathrm{~nm}$, i.e., the same average diameter as typical presynaptic small vesicles. These vesicles had a clear content and were sometimes organized in clusters (Fig. 1, b-d). In addition, scattered large dense-core vesicles (Hökfelt et al., 1986; De Camilli and Navone, 1987) were also observed. The plasmalemma of the distal portion of the calyx was parallel to the plasmalemma of the "neck" of the hair cell (Fig. 1c), but structural specializations with the characteristics of synapticlike contacts were not seen.

The neck of the hair cell was characterized by the presence of parallel-aligned, tightly packed microtubules oriented along the major axis of the cell (Fig. $1 b$ ).

\section{Immunocytochemistry}

Bright focal accumulations of synaptophysin immunoreactivity was observed in the juxtaluminal portion of the epithelia of the 3 species examined (Fig. 2, $a-d$ ). This immunoreactivity appeared to surround the neck of type I sensory cells, thus appearing in the form of ring structures in tangential sections of the epithelium (Fig. $2 b$ ) and of $\mathrm{V}$-shaped structures in cross sections (Fig. 2, $c, d$ ). Such immunoreactive structures precisely matched the expected morphology of the apical portion of the calyces. Bright puncta of synaptophysin immunoreactivity were also observed around the basal portion of sensory hair cells. The distribution of these puncta corresponded to the known distribution of efferent nerve endings (Raymond and Demêmes, 1983). The distribution of synaptophysin immunoreactivity in vestibular epithelia was quite similar, if not identical, to the distribution of synapsin I immunoreactivity (Fig. $2 e$; see also Favre et al., 1986) (1). Control sections were unstained, as shown on Figure $2 f$.

\section{Discussion}

Early electron microscopic studies of the vestibular sensory epithelium noted the presence of scattered pleiomorphic vesicular profiles in nerve calyces has been mentioned (Smith, 1956; Hamilton, 1968; Engström et al., 1972). The physiological role of these vesicles, however, remained elusive. The finding that calyces contain a high concentration of synapsin I (Favre et al., 1986), a protein found in high concentration on synaptic vesicles involved in release of classical neurotransmitters (De Camilli et al., 1983a, b; Huttner et al., 1983), raised the possibility that vesicles related to presynaptic vesicles might be present in these nerve endings commonly considered to be only afferent. However, synapsin I is not a bona fide intrinsic membrane protein. It is synthesized on free ribosomes (De Gennaro et al., 1983), it can be dissociated from purified synaptic vesicles by increasing the ionic strength of the suspending medium, and it can bind not only to vesicles but also to various components of the cytoskeleton (Baines and Bennett, 1985; Bähler and Greengard, 1987; see De Camilli and Greengard, 1986, for a review). Thus, in principle, the presence of synapsin $I$ in afferent calyces did not necessarily imply the presence of synaptic vesicles also. The results presentcd herc, howcver, argue in favor of their presence. By employing a fixation procedure specially designed to preserve the ultrastructure of nerve endings of the vestibular sensory epithelium and by focusing our attention on regions of the calyx previously found to be rich in synapsin I immunoreactivity, we found an abundant population of vesicles morphologically identical to typical presynaptic vesicles in the nerve calyces. Furthermore, we found that synaptophysin is also present in the apical portion of the calyces. In neurons, synaptophysin is colocalized with synapsin I on the membrane of small synaptic vesicles (Jahn et al., 1985; Wiedenmann and Franke, 1985; Navone et al., 1986). Unlike synapsin I, synaptophysin is an integral transmembrane protein (Jahn et al., 1985; Wiedenmann and Franke, 1985; Leube et al., 1987; Südhof et al., 1987).

Could the microvesicles of afferent calyces be involved in

Figure 1. Electron micrographs illustrating the presence of microvesicles in the upper portion of vestibular nerve calyx. $a$, Apical portion of a mouse type I hair cell (HC) showing numerous microvesicles with clear content (arrowheads) and large dense-core vesicles (arrows). NC, nerve calyx. $b$. Thick $(150 \mathrm{~nm})$ section of the apical portion of a type I hair cell of a cat vestibular epithelium. Numerous microvesicles sometimes aggregated in clusters are concentrated in the liplike endings of the calyx. Note the presence of densely packed, parallel microtubules in the neck of the hair cell enclosed by the lips of the calyx. $c$ and $d$, High-power view of the apical portion of 2 cat nerve calyces showing the prominent population of clear microvesicles and few large dense-core vesicles (arrow). Scale bars, $0.5 \mu \mathrm{m}$.

Figure 2. Immunocytochemical localization of synaptophysin $(a-d)$ and of synapsin I $(e)$ in frozen (10- $\mu \mathrm{m}$-thick) and plastic (1- $\mu \mathrm{m}-$ thick) sections of vestibular sensory epithelia. $a$, immunofluorescence, transverse frozen section of mouse crista; $b$, immunoperoxidase, tangential frozen section of rat utricle; $c$, immunofluorescence, transverse frozen section of cat utricle; $d$ and $e$, immunofluorescence, transverse plastic section of cat utricle. In transverse sections of epithelium stained for either synaptophysin and synapsin I, bright puncta of immunoreactivity are visible at the base of hair cells (arrows). These puncta very likely represent efferent nerve endings. In addition, a lower level of immunoreactivity appears to enwrap hair cells. This immunoreactivity is more intense around their apex, i.e., in correspondence with the terminal lips of the nerve calyces (arrowheads). In this region, $\mathrm{V}$-shaped structures are seen $(c-e)$. Such structures represent longitudinal sections of the apical portion of the calyces. A low-level fluorescence is visible in the cytoplasm of hair cells in $a, c$, and $d$ but not in $e$. [A low concentration of synaptophysin, but not of synapsin I, was also observed in the cytoplasm of type $I$ hair cells. This observation is reminiscent of the observation that synaptophysin (Navone et al., 1986, and De Camilli et al., unpublished observations) but not synapsin I (De Camilli et al., 1983a) is localized in retinal photoreceptors.] In tangential section of the epithelium $(b)$, dark immunoreactive circles ( 2 of which are indicated by arrowheads) represent cross sections of the apical portions of the calyces enclosing the unstained neck of hair cells (arrowhead level in $c$ ). $f$, Control staining showing a transverse frozen section of a mouse utricle, with the apical and basal regions of a hair cell indicated by the arrowhead and arrow, respectively. Scale bars, $10 \mu \mathrm{m}$. 

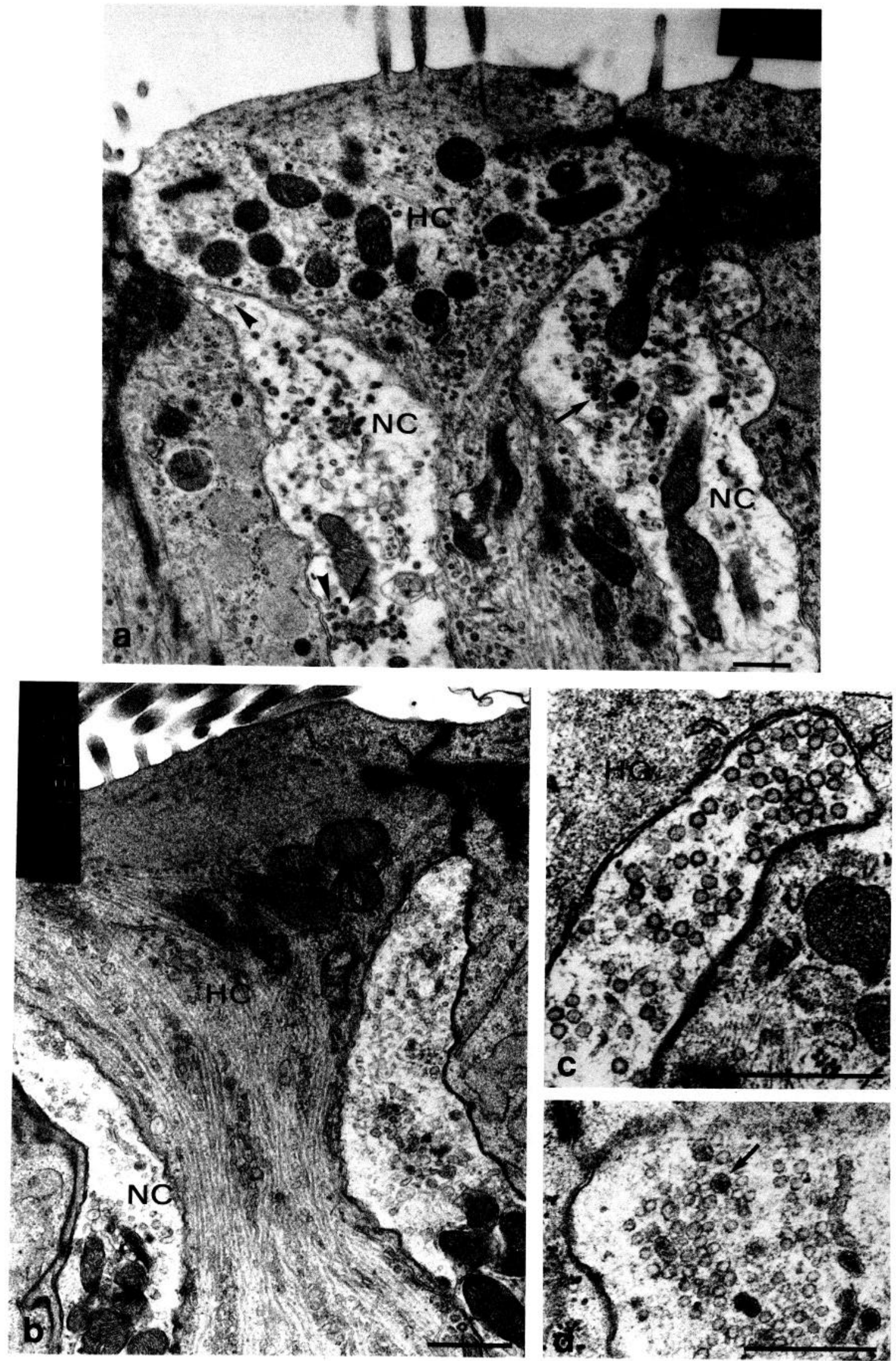

Figure 1. 

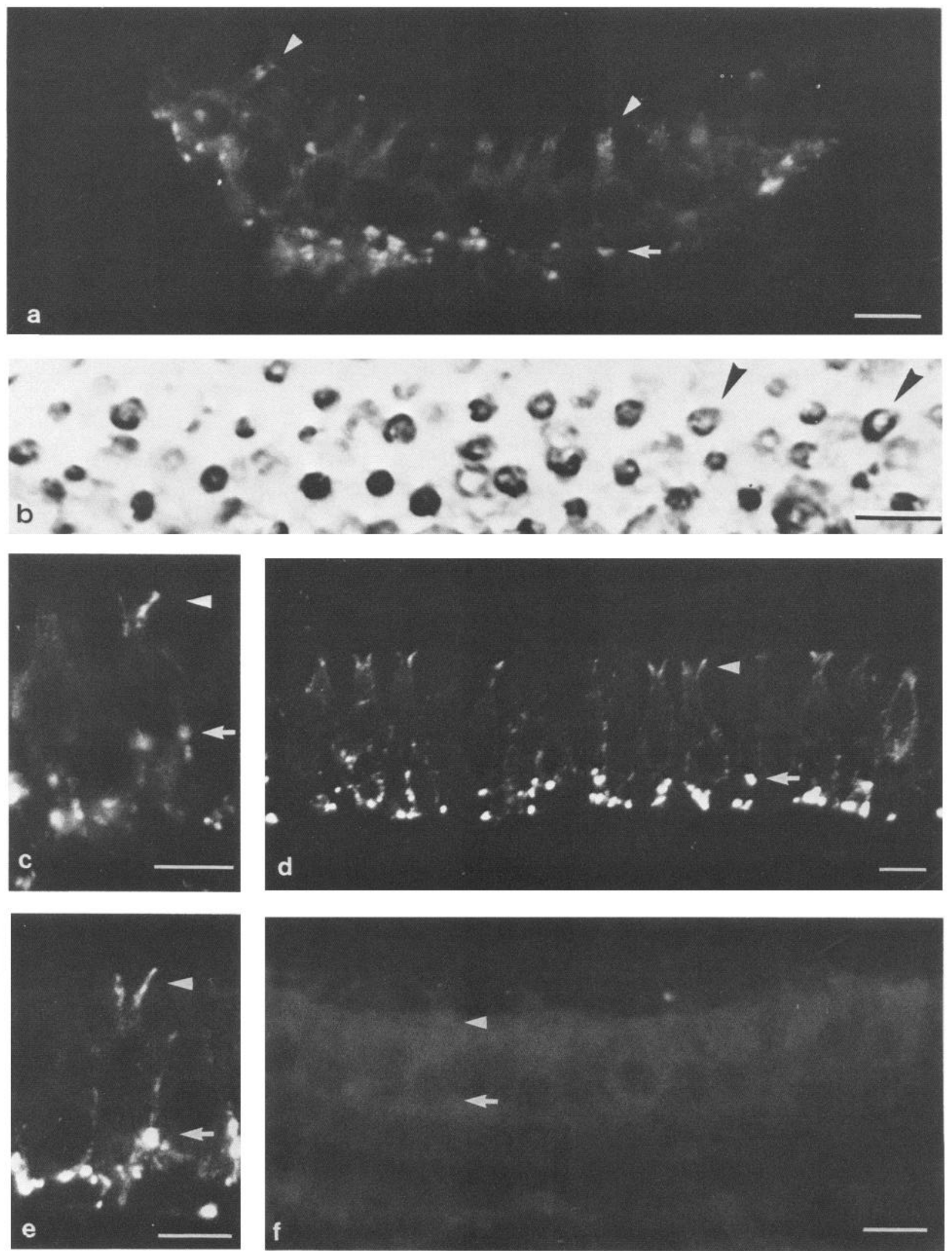

Figure 2. 
release of classical neurotransmitters? The presence of synapsin I and of synaptophysin in their membrane, as suggested by our experiments, indicates that they may be biochemically related to presynaptic small synaptic vesicles that contain classical neurotransmitters (Hökfelt et al., 1986; De Camilli and Navone, 1987) and therefore supports this possibility. The lack of recognizable synaptic contacts between the microvesicle-rich region of the calyces and the hair cells does not necessarily speak against a secretory function of the calyx. Release of classical neurotransmitters via exocytosis of small vesicles outside typical synaptic sites is known to take place at various regions of the CNS and PNS (Beaudet and Descarries, 1978; Schipper et al., 1980). This type of release is thought to be involved in modulatory phenomena (Reader et al., 1979). We have also observed the presence of large dense-core vesicles in the calyces, i.e., the vesicles involved in the release of peptide neurotransmitters (Hökfelt et al., 1986; De Camilli and Navone, 1987). These findings further support the hypothesis that sensory calyces also have a secretory function. Indeed, evidence for release of peptides from peripheral endings of primary afferent fibers has been previously shown (Olgart et al., 1977; Cuello et al., 1978; Lembeck, 1983), and exocytotic profiles of large dense-core vesicles away from typical synaptic membrane specialization have been reported (Zhu et al., 1986). Thus, the preliminary observation of Ylikoski et al. (1984) suggesting the presence of substance P-like immunoreactivity in the nerve calyx is of special interest in the context of the present findings.

We have recently found that sensory endings of striated muscles and of tendons also contain high concentrations of synaptophysin and synapsin I (De Camilli et al., 1985, 1988). The possibility should be considered that many, and perhaps all, peripheral afferent nerve endings might have secretory properties.

Vesicle-rich endings of afferent fibers contacting type II hair cells have been observed in mammalian vestibular maculas (Ross, 1985). It has been postulated, on the basis of observations on serial sections, that these endings originate from calyceal collaterals. In view of our results, this possibility should be further investigated. If this is the case, the nerve calyx and its collaterals may participate in a complex, intraepithelial communication network.

Immunocytochemical detection of cytoskeletal elements in the apex of inner ear hair cells (Drenckhahn et al., 1985; Scarfone et al., 1988) and micromanipulation experiments demonstrating contractile properties of hair cells (Orman and Flock, 1983; Flock et al., 1986) have suggested that mechanoelectrical transduction in hair cells may be subjected to some kind of regulation. The possibility that vestibular nerve calyces might be able to secrete modulatory substances at the level of the input end of vestibular hair cells suggests a way by which this regulation might be accomplished.

In conclusion, we hypothesize that the basal and apical portions of the calyces are primarily involved in distinct functions. The basal portion, where a specialized junctional complex is formed between the calyx and the base of the hair cells, is the region where signals are transferred from the hair cell to the nerve fiber. The apical portion of the calyx, which surrounds the neck of the hair cell, has a secretory function and transfers signals from the sensory fiber to the hair cell. According to this hypothesis, the calyx might be involved in a short-loop feedback control of type I hair cells.

\section{References}

Bähler, M., and P. Greengard (1987) Synapsin I bundles F-actin in a phosphorylation-dependent manner. Nature 326: 704-707.

Baines, A. J. and V. Bennett (1985) Synapsin I is a spectrin-binding protein immunologically related to erythrocyte protein 4.1 . Nature 315: $410-413$.

Beaudet, A., and L. Descarries (1978) The monoamine innervation of rat cerebral cortex: Synaptic and nonsynaptic axon terminals. Neuroscience 3: 851-860.

Cuello, A. C., M. Del Fiacco, and G. Paxinos (1978) The central and peripheral ends of the substance P-containing sensory neurones in the rat trigeminal system. Brain Res. 152: 499-509.

De Camilli, P., and P. Greengard (1986) Synapsin I: A synaptic vesicleassociated neuronal phosphoprotein. Biochem. Pharmacol. 35:43494357.

De Camilli, P., and F. Navone (1987) Regulated secretory pathways of neurons and their relation to the regulated secretory pathway of endocrine cells. Ann. NY Acad. Sci. 493: 461-479.

De Camilli, P., R. Cameron, and P. Greengard (1983a) Synapsin I (Protcin I), a ncrve terminal-spccific phosphoprotcin. I. Its general distribution in synapses of the central and peripheral nervous system demonstrated by immunofluorescence in frozen and plastic section. J. Cell Biol. 96: 1337-1354.

De Camilli, P., S. M. Harris, Jr., W. B. Huttner, and P. Greengard (1983b) Synapsin I (Protein I), a nerve terminal-specific phosphoprotein. II. Its specific association with synaptic vesicles demonstrated by immunocytochemistry in Agarose-embedded synaptosomes. J. Cell Biol. 96: 1355-1373.

De Camilli, P., P. E. Miller, P. Levitt, U. Walter, and P. Greengard (1984) Anatomy of cerebellar purkinje cells in the rat determined by a specific immunohistochemical marker. Neuroscience 11:761-817.

De Camilli, P., M. P. Canevini, R. Zanoni, M. Vitadello, C. Triban, and $A$. Gorio (1985) Synapsin $I$ is present in both efferent and afferent nerve cndings in skclctal muscle. Abstracts 15th Annual Meeting of the Society for Neurosciences, p. 1131.

De Camilli, P., M. Vitadello, M. P. Canevini, R. Zanoni, R. Jahn, and A. Gorio (1988) The synaptic vesicle proteins synapsin I and synaptophysin (protein 38) are concentrated both in efferent and afferent nerve endings of the skeletal muscle. J. Neurosci. 8: 1625-1631.

De Gennaro, L. J., S. Kanazir, W. C. Wallace, R. M. Lewis, and P. Greengard (1983) Neuron-specific phosphoproteins as models for neuronal gene expression. Cold Spring Harbor Symp. Quant. Biol. 48: 337-345.

Drenckhahn, D., T. Schafer, and M. Prinz (1985) Actin, myosin, and associated proteins in the vertebrate auditory and vestibular organs: Immunocytochemical and biochemical studies. In Auditory Biochemistry, D. G. Drescher, ed., pp. 317-335, Charles C Thomas, Springficld, IL.

Engström, H., B. Bergström, and H. W. Ades (1972) Macula utriculi and macula sacculi in the Squirrel Monkey. Acta Otolaryngol. (Stockh.) (Suppl.) 301: 75-126.

Favre, D., and A. Sans (1979) Morphological changes in afferent vestibular hair cell synapses during the postnatal development of the cat. J. Neurocytol. 8: 765-775.

Favre, D., and A. Sans (1983) A fixation technique for better ultrastructural preservation of nerve endings in the vestibular sensory epithelium-A TEM and X-ray microanalysis study. Micron Microscop. Acta 14: 319-327.

Favre, D., E. Scarfone, G. Di Gioia, P. De Camilli, and D. Demêmes (1986) Presence of synapsin I in afferent and efferent nerve endings of vestibular sensory epithelia. Brain Res. 384: 379-382.

Flock, A., B. Flock, and M. Ulfendahl (1986) Mechanisms of movement in outer hair cells and a possible structural basis. Arch. Otorhinolaryngol. 243: 83-90.

Hamilton, D. W. (1968) The calyceal synapse of type I vestibular hair cells. J. Ultrastruct. Res. 23: 98-114.

Hökfelt, T., V. R. Holets, W. Staines, B. Meister, T. Melander, M. Schalling, M. Schultzberg, J. Freedman; H. Björklund, L. Olson, B. Lindh, L.-G. Elfin, J. M. Lundberg, J. A. Lindgren, B. Samuelsson, B. Pernow, L. Terenius, C. Post, B. Everitt, and M. Goldstein (1986) Coexistence of neuronal messengers-an overview. Prog. Brain Res. 68: 33-70.

Huttner, W. B., W. Schiebler, P. Greengard, and P. de Camilli (1983) 
Synapsin I (Protein I), a nerve terminal-specific phosphoprotein. III. Its association with synaptic vesicles studied in a highly purified synaptic vesicle preparation. J. Cell Biol. 96: 1374-1388.

Jahn, R., W. Schiebler, C. Ouimet, and P. Greengard (1985) A 38,000dalton membrane protein (p38) present in synaptic vesicles. Proc. Natl. Acad. Sci. USA 82: 4137-4141.

Lembeck, F. (1983) Sir Thomas Lewis's nocifensor system, histamine and substance-P-containing primary afferent nerves. T.I.N.S. 6: 106.

Leube, R. E., P. Kaiser, A. Seiter, R. Zimbelmann, W. W. Franke, H. Rehm, P. Knaus, P. Prior, H. Betz, H. Reinke, K. Beyreuther, and B. Wiedenmann (1987) Synaptophysin: Molecular organization and mRNA expression as determined from cloned cDNA. EMBO J. 6: 3261-3268.

Navone, F., P. Greengard, and P. De Camilli (1984) Synapsin I in nerve terminals: Selective association with small synaptic vesicles. Science 226: 1209-1211.

Navone, F., R. Jahn, G. Di Gioia, H. Stukenbrok, P. Greengard, and P. De Camilli (1986) Protein p38: An integral membrane protein specific for small vesicles of neurons and neuroendocrine cells. J. Cell Biol. 103: 2511-2527.

Olgart, L., B. Gazelius, E. Brodin, and G. Nilson (1977) Release of substance P-like immunoreactivity from the dental pulp. Acta Physiol. Scand. $101: 510-512$.

Orman, S., and A. Flock (1983) Active control of sensory hair mechanics implied by susceptibility to media that induce contraction in muscle. Hearing Res. 11: 261-266.

Raymond, J., and D. Dememes (1983) Efferent innervation of vestibular receptors in the cat: A radioautographic visualization. Acta Otolaryngol. (Stockh.) 96: 413-419.

Reader, T. A., A. Ferron, L. Descarries, and H. H. Jasper (1979) Mod- ulatory role for biogenic amines in the cerebral cortex.' Microiontophoretic studies. Brain Res. 160: 217-229.

Ross, M. D. (1985) Anatomic evidence for peripheral neural processing in mammalian graviceptors. Aviat. Space Environ. Med. 56: 338-343.

Scarfone, E., D. Demêmes, D. Perrin, D. Aunis, and A. Sans (1988) $\alpha$-Fodrin (brain spectrin) immunocytochemical localization in vestibular hair cells. Neurosci. Lett. (in press).

Schipper, J., F. J. H. Tilders, and A. H. Mulder (1980) Extraneuronal cathecholamine in the iris of the rat: A consequence of nonsynaptic neurotransmission? Neuroscience 5: 745-751.

Smith, C. A. (1956) Microscopic structure of the utricle. Ann. Otol. 65: $450-469$.

Südhof, T. C., F. Lottspeich, P. Greengard, E. Mehl, and R. Jahn (1987) A synaptic vesicle protein with a novel cytoplasmic domain and four transmembrane regions. Science 238: 1142-1143.

Wersäll, J., and D. Bagger-Sjöbäck (1974) Morphology of the vestibular sense organ. In IIandbook of Sensory Physiology, Vol. 6, II. II. Kornhuber, ed., pp. 123-170, Springer-Verlag, New York.

Wiedenmann, B., and W. W. Franke (1985) Identification and localization of synaptophysin, an integral membrane glycoprotein of $\mathrm{Mr}$ 38,000 characteristic of presynaptic vesicles. Cell 41: 1017-1028.

Ylikoski, J., H. Päivärinta, L. Eränkö, I. Mrena, and J. Lehtosalo (1984) Is substance $P$ the neurotransmitter in the vestibular end-organs? Acta Otolaryngol. (Stockh.) 97: 523-528.

Zhu, P. C., A. Thureson-Klein, and R. L. Klein (1986) Exocytosis from large dense cored vesicles outside the active synaptic zones of terminals within the trigeminal subnucleus caudalis: A possible mechanism for neuropeptide release. Neuroscience 19: 43-54. 